\title{
Homeostasis in Topical Photoprotection: Getting the Spectral Balance Right
}

\author{
Fernando Stengel ${ }^{1}$
}

Published online: 30 October 2018

(c) The Author(s) 2018

\begin{abstract}
The solar radiation range has harmful and beneficial effects. Sunscreens, which selectively block specific spectral regions, may potentially interfere with skin homeostasis. For instance, the ultraviolet (UV) B waveband produces erythema and DNA damage; simultaneously, it induces pre-vitamin $\mathrm{D}_{3}$ synthesis. UVA1 and visible light can both induce pigmentation in skin phototypes IV-VI, and act in synergy to induce erythema and persistent pigment darkening. In contrast, UVA may contribute to blood pressure control and cardioprotection by inducing release of nitric oxide from intracutaneous photolabile nitric oxide derivatives. Finally, infrared A radiation alters the collagen equilibrium of the dermal extracellular matrix but is involved in the regulation of body temperature and in nitric oxide release, with a potential beneficial impact on blood pressure regulation. Ideally, photoprotection should thus be performed with a neutral density filter, mitigating all radiation ranges homogeneously, to maintain solar spectrum homeostasis. Natural compounds such as mycosporine-like amino acids are promising natural UV radiation-filtering compounds for an improved homeostasis with our environment. Lastly, we should not forget individual characteristics and behavior, as homeostasis differs according to individual phototypes and skin exposure behaviors.
\end{abstract}

\section{Key Points}

Spectral homeostasis is a desirable goal because all solar radiation (ultraviolet, infrared, and visible light) can both affect the skin and have beneficial effects contributing to human health.

The ideal photoprotector to maintain solar spectrum homeostasis should be a neutral density filter mitigating all radiation ranges homogeneously.

\section{Introduction}

The concept of 'spectral and skin homeostasis' applied to sunscreens is a developing notion, which will impact on topical formulations in the near future. It refers to the fact that the continuous use of sunscreens that filter particular

Fernando Stengel

fernando@stengeldermato.com.ar

1 Buenos Aires Skin, Avenida Cordoba 1184, 10 Piso. (1055), Ciudad Autónoma de Buenos Aires, Argentina solar wavelengths may be altering skin homeostasis on a daily basis.

Spectral homeostasis, in particular, would mean leaving the natural solar spectrum unchanged, even though attenuated by sunscreen, clothing, or shading structures. Spectral homeostasis is a desirable goal for two reasons: (1) not only ultraviolet (UV) radiation (UVR), but also infrared radiation (IR) and visible light (VL), i.e., the total solar spectrum, can affect the skin; and (2) the biological effects of solar radiation also include beneficial effects, contributing to human health. This article focuses on the beneficial aspects of solar electromagnetic radiation (EMR) on the skin and the recent developments of research on this topic.

\section{Solar Exposure and Skin Homeostasis}

The solar radiation reaching the top of the earth's atmosphere is composed of only 5-7\% of UVR, which covers the wavelength range $100-400 \mathrm{~nm}$ and is divided into three bands: UVC (100-280 nm), UVB (280-315 nm), and UVA $(315-400 \mathrm{~nm})[1,2]$. Through the atmosphere, all UVC and approximately $90 \%$ of UVB radiation is absorbed, so that the UVR reaching the earth's surface is mainly composed of 
UVA, with a small UVB fraction. Visible radiation, which covers the wavelength range $400-780 \mathrm{~nm}$, accounts for $45 \%$ of solar radiation, while IR, composed of wavelengths longer than $780 \mathrm{~nm}$, represents the remaining $48-50 \%$.

UV, VL, and IR radiation have different energy values and degrees of penetration into the skin [3]. Cutaneous effects are produced by the whole spectrum of EMR, in the UV, VL, and IR ranges, and may thus produce negative effects at all levels of the skin from the epidermis to the deep dermis [4].

\subsection{Ultraviolet (UV) Exposure and Skin Homeostasis}

Excessive solar exposure of the skin can lead to different types of damage, including sunburn (erythema), photoaging, and skin cancer. Erythema is an important factor in the pathogenesis of melanoma and keratinocyte skin cancers [5]. As such, UVR protection by various measures, including sunscreen, is largely recommended by international guidelines [6] and the World Health Organization (WHO) has defined a UV index (UVI) to encourage photoprotection in skin cancer prevention campaigns [1].

\subsubsection{UVB Radiation and Pre-Vitamin D Biosynthesis}

The influence of UVB has been the subject of much debate. The strict UVB protection recommended by several guidelines is now questioned, since it could be associated with vitamin D deficiency [7-10]. Dietary supplementation with low-dose vitamin D (<400 IU) during the whole year can at least partly counteract the lack of solar exposure by maintaining adequate levels $(25-\mathrm{OH}$ vitamin $\mathrm{D}$ of $50 \mathrm{nmol} / \mathrm{L}$ ) or reduction of winter declines [11].

The fact that the action spectra (wavelength dependence) of both harmful (erythema, DNA damage induction) and beneficial phenomena (cutaneous pre-vitamin $\mathrm{D}_{3}$ synthesis) overlap (Fig. 1) questions the logic of a long-lasting evolutionary process of gene interaction with the environment. However, this apparent dilemma can be understood: (1) pre-vitamin $\mathrm{D}_{3}$ production does not require long periods of UVB irradiation; and (2) UVB radiation overexposure induces sunburn, a painful warning that prompts subsensitive individuals to reduce or avoid sun exposure.

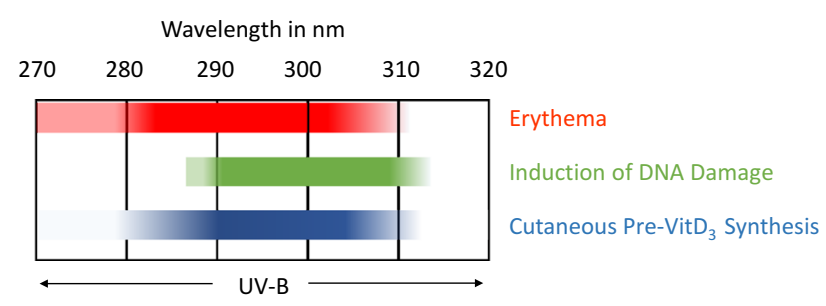

Fig. 1 Overlap between beneficial (cutaneous pre-vitamin $\mathrm{D}_{3}$ synthesis [41]) and harmful action spectrum (erythema action spectrum [42] and induction of DNA damage [43])
Since UVR is both the best natural source of vitamin D and a major cause of skin cancer, there is thus a fine line in balancing these beneficial and harmful effects. As pictured in Fig. 2, homeostasis stands at the crossroads between the good, the bad, and the necessary effects of EMR. This has led to new approaches to develop optimized sunscreens that enable vitamin $\mathrm{D}$ formation with reduced erythema risk [12].

\subsubsection{UVA Radiation and Blood Pressure}

Independently of vitamin D production, UVR can also play a role in health via other mechanisms [13], such as improvement of mood through the release of endorphins [14] and alleviation of the symptoms of multiple sclerosis [15]. In particular, epidemiological data show than sun exposure is inversely correlated with the incidence of hypertension and cardiovascular disease mortality [16] and this hypotensive effect is not related to vitamin D, since oral vitamin D supplementation does not influence blood pressure patterns [17]. In Southern Europe, 30 min of solar exposure at midday on a sunny day can induce vasodilatation of the arterial vasculature. This effect is UVA-mediated and independent from skin temperature and warming by the sun [18]. Insights into the mechanism were brought by Oplander et al. in 2009 [19]. They showed that whole-body UVA exposure lowers systemic blood pressure by release of nitric oxide (NO) from intracutaneous photolabile NO derivatives, and that UVA skin irradiation can increase plasma nitrite $\left(\mathrm{NO}_{2}\right)$ levels by $40 \%$.

The role played by the epidermis is linked to its very rich content in cysteine-containing proteins. Their sulfhydryl groups readily undergo nitrosation to form endogenous nitrite and S-nitrosothiols (RSNOs). Nitrate $\left(\mathrm{NO}_{3}\right), \mathrm{NO}_{2}$, and RSNOs are present in the dermis and epidermis at concentrations one or two orders of magnitude higher than in plasma [20].

NO can act through several mechanisms. Palmer et al. [21] showed as early as 1987 that NO release accounts for the biological activity of endothelium-derived relaxing

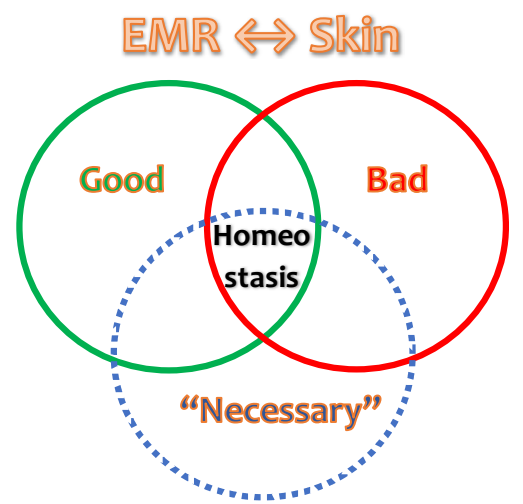

Fig. 2 Homeostasis of solar radiation. Between electromagnetic radiation (EMR) and the skin, homeostasis can be found at the intersection between good, bad, and 'necessary' effects of solar radiation 
factor (EDRF). Besides, NO can also play a role on the peripheral vascular resistance via the differential expression of the hypoxia-inducible factor- $\alpha(\mathrm{HIF}-\alpha)$ isoforms in the skin, which are correlated with the degree of idiopathic hypertension in humans [22].

Many questions remain, such as the importance of UVAmediated photolysis in blood pressure control, precisely how different wavelengths interact with NO-related species, and what is the subsequent fate of the reaction products? Is this UVA-mediated mechanism effective independent of age and gender in hypertensive individuals, through repeated stimulus [23]? However, since high blood pressure is the leading cause of premature death and disease worldwide, according to the WHO's most recent survey [24], the hypotensive effect of UVA exposure [25] and the potential interference of UVA-skin interactions by sunscreens merits further investigation. Indeed, the UVA spectrum is responsible for $>80 \%$ of NO released [18].

\subsection{Visible Light and Skin Homeostasis}

Long thought to be 'innocuous', VL was recently shown to be able to induce persistent pigment darkening and DNA damage via reactive oxygen species and to exacerbate some photodermatoses. Although UVA1 (340-400 nm) can also induce pigmentation in skin phototypes IV-VI, VL-induced pigmentation is darker and more persistent [26]. Moreover, VL acts in synergy with UVA1 to induce erythema and pigmentation [27].

\subsection{Infrared Radiation and Skin Homeostasis}

IR is involved in several biological mechanisms. Although IRA (700-1400 nm) may decrease collagen synthesis in the dermal extracellular matrix by increasing the expression of the collagen-degrading enzyme, matrix metalloproteinase 1 (MMP-1), workers exposed to industrial sources of IR in amounts comparable to typical annual levels of IRA solar exposure do not experience significant long-term skin damage [28]. In addition, IRA is involved in the regulation of body temperature and in NO release, with a potential beneficial impact on blood pressure and possibly on cardioprotection [29]. There is therefore a need for quantitative analysis of the benefits, if any, of incorporating agents into sunscreens that reduce cutaneous IRA damage [30].

\section{Sunscreen Spectrum Homeostasis}

Sunscreens are used to provide 'adequate' protection against the damage induced by EMR. Current sunscreens, based on combinations of filters, are able to block almost all the UVR spectral range, nearly as efficiently as protection by clothing (Fig. 3) [31, 32]. Protection against VL can be provided by compact powders, which are added in blemish balm or color-correcting creams (Fig. 4). However, what about IR? No standardized tests provide a basis for the claims made for some products. Solar protection should not impede the

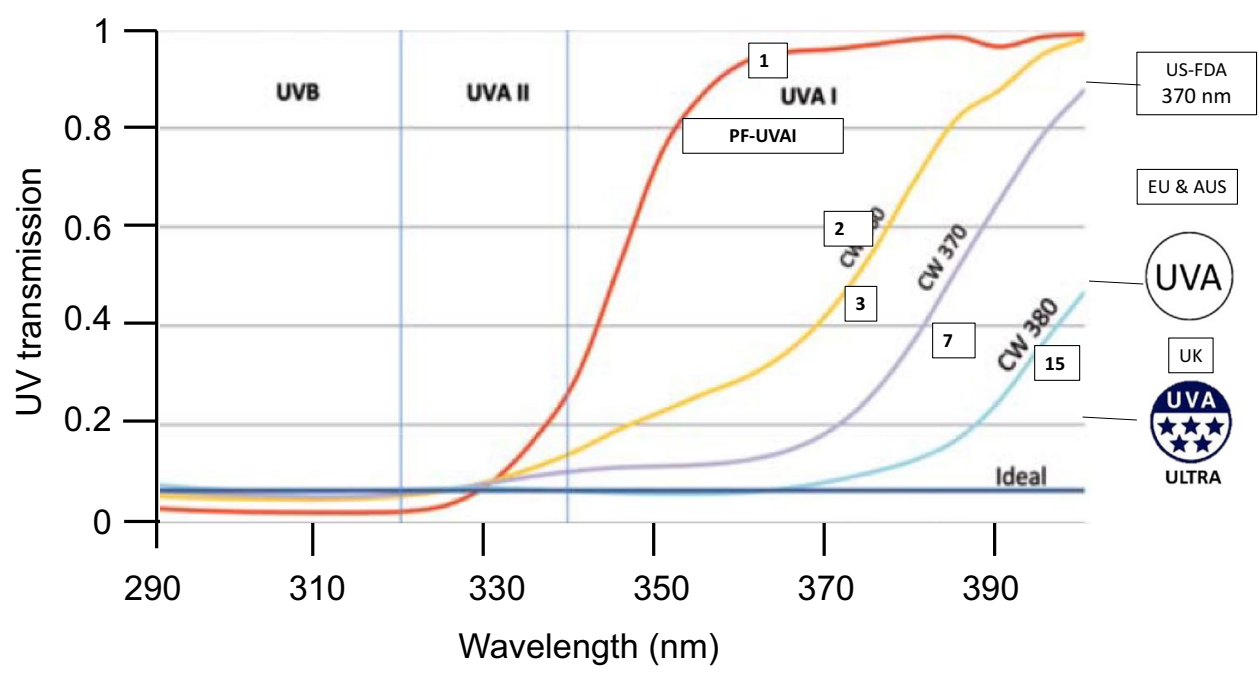

Fig. 3 Protection profile of optimal daily UVR protection versus other day creams or sunscreens (all SPF 15), with various UVA1-PF, corresponding to various $\mathrm{CW}$. Red line: day cream focused on UVB protection; yellow line: sunscreen with $\mathrm{CW} 360 \mathrm{~nm}$; purple line: sunscreen with CW $370 \mathrm{~nm}$; light blue line: optimal daily UV protection CW $380 \mathrm{~nm}$; dark blue line: ideal sunscreen profile (protection by clothing and garments). Numbers in boxes stand for UVA1-PF. Logos stand for various UVA standards depending on countries [US FDA:
US standards ( $\mathrm{CW}=370 \mathrm{~nm}$ only); EU: Europe $(\mathrm{CW} \geq 370 \mathrm{~nm}$ and UVA-PF:SPF ratio $>0.33)$; AUS: transmission $<10 \%(320-360 \mathrm{~nm})$; UK: United Kingdom $(\mathrm{CW} \geq 370 \mathrm{~nm}$ and Boots 5-star rating UVA/ UVB $\geq 0.9$ )]. Adapted from Osterwalder et al. [32] with permission. AUS Australia, $C W$ critical wavelengths, $E U$ European Union, $F D A$ Food and Drug Administration, $S P F$ sun protection factor, UV ultraviolet, $U V A-P F$ ultraviolet A protection factor, $U V A 1-P F$ ultraviolet A1 protection factor, $U V R$ ultraviolet radiation 
Fig. 4 Protection spectrum against solar radiation. $I R$ infrared radiation, $S P F$ sun protection factor, $U V A-P F$ UVA protection factor

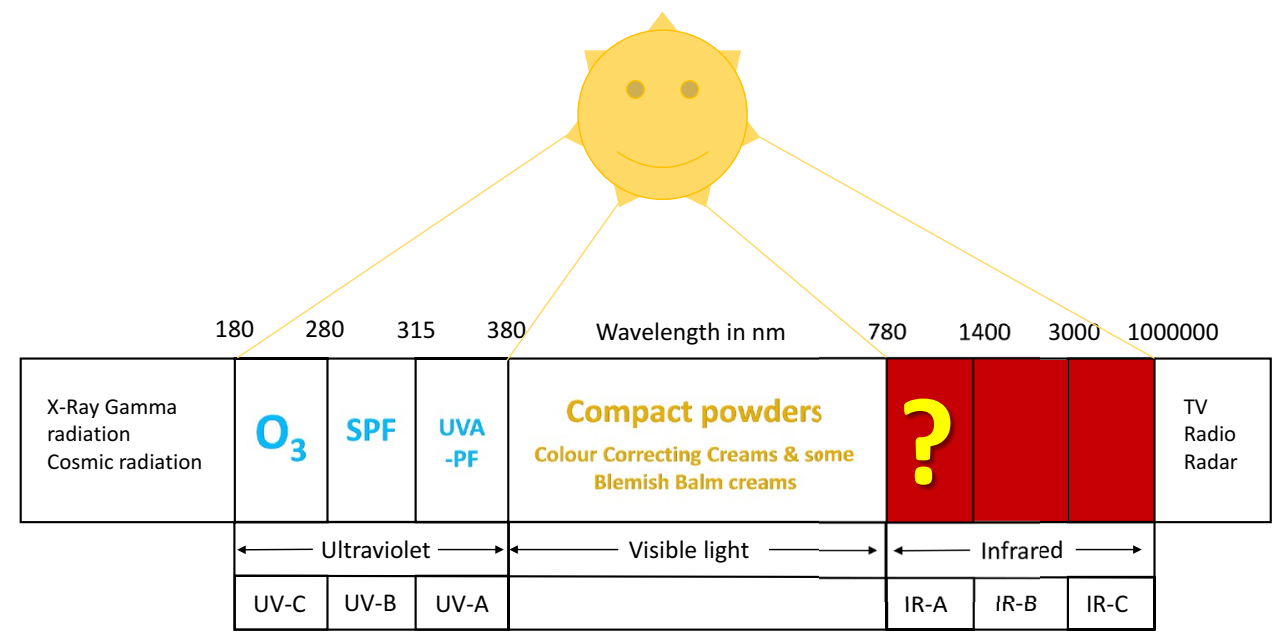

beneficial functional skin responses, which result from EMR and skin interactions. The advent of the concept of skin homeostasis calls, therefore, for the development of sunscreens ensuring uniform spectral absorbance across the UV and global solar spectrum (Fig. 4). The recognition that the addition of VL and IRA to the regular solar-simulated radiation (SSR) used in sun protection factor (SPF) testing may influence the minimal erythema dose and SPF results further emphasizes the importance of global spectrum protection [33].

The concept of sunscreen homeostasis also considers the homeostasis with our environment. As shown by Ramos et al. [34], who reviewed the presence of organic UVR filters in wastewater treatment plants in Portugal, there is a need for the development of ecological solar UVR filters, based on naturally occurring filters. Natural compounds can offer photostable wide-spectrum filters, with reduced ecotoxicity and adverse effects [35]. Several species, including aquatic organisms, produce small molecules that protect them from the sun by absorbing harmful UVR, such as UV-absorbing mycosporine-like amino (MMA) acids [36].

Besides, it should be remembered that sunscreens do not address a homogeneous target population. Skins of different phototypes differ in their photobiological responses, including DNA repair, immunosuppression, apoptosis, anti-oxidative capabilities, and photoaging [37]. Differences in the melanocortin 1 receptor and in skin pigments are involved in the susceptibility to skin cancer [38]. Personalized photoprotection recommendations concerning skin cancer risk factors, desired treatment outcomes, health needs (e.g., vita$\min \mathrm{D})$, and photoaging, based on the needs and preferences of the patient, are therefore essential [39].

Last but not least, on our way to sun-skin homeostasis, we should not forget that the most imponderable aspect is the human factor, based on beliefs, behaviors, and conduct. With individual exposure ranging from nearly total to minimal skin coverage, the challenge will surely require improved photoprotection strategies such as systemic photoprotectants and, ideally, universal photoeducation campaigns [40].

Acknowledgments Special thanks to Dr Uli Osterwalder for his helpful discussions on homeostasis. We also thank Françoise Nourrit-Poirette and Marielle Romet (Santé Active Edition) who provided medical writing assistance on behalf of Laboratoires dermatologiques Avène.

\section{Compliance with Ethical Standards}

Funding Medical writing assistance was funded by Laboratoires dermatologiques Avène. Prof. Fernando Stengel received funds from Laboratoires dermatologiques Avène for traveling to and presenting at the conference.

Conflict of interest Fernando Stengel declares that he has no conflicts of interest that might be relevant to the contents of this manuscript.

Disclosure statement This article is published as part of a journal supplement wholly funded by Laboratoires dermatologiques Avène.

Open Access This article is distributed under the terms of the Creative Commons Attribution-NonCommercial 4.0 International License (http://creativecommons.org/licenses/by-nc/4.0/), which permits any noncommercial use, distribution, and reproduction in any medium, provided you give appropriate credit to the original author(s) and the source, provide a link to the Creative Commons license, and indicate if changes were made.

\section{References}

1. WHO. Global Solar UV Index: a practical guide. A joint recommendation of the World Health Organization, World Meteorological Organization, United Nations Environment Programme, and the International Commission on Non-Ionizing Radiation Protection. Geneva: WHO; 2002.

2. United Nations Environment Programme EEAP. Environmental effects of ozone depletion and its interactions with climate change: progress report, 2016. Photochem Photobiol Sci. 2017;16(2):107-45. 
3. Dupont E, Gomez J, Bilodeau D. Beyond UV radiation: a skin under challenge. Int J Cosmet Sci. 2013;35(3):224-32.

4. Krutmann J, Bouloc A, Sore G, Bernard BA, Passeron T. The skin aging exposome. J Dermatol Sci. 2017;85(3):152-61.

5. D'Orazio J, Jarrett S, Amaro-Ortiz A, Scott T. UV radiation and the skin. Int J Mol Sci. 2013;14(6):12222-48.

6. Schalka S, Steiner D, Ravelli FN, Steiner T, Terena AC, Marcon $\mathrm{CR}$, et al. Brazilian consensus on photoprotection. An Bras Dermatol. 2014;89(6 Suppl 1):1-74.

7. Holick MF. Vitamin D deficiency. $N$ Engl J Med. 2007;357(3):266-81.

8. Wacker M, Holick MF. Sunlight and Vitamin D: a global perspective for health. Dermatoendocrinol. 2013;5(1):51-108.

9. Deluca HF. History of the discovery of vitamin D and its active metabolites. Bonekey Rep. 2014;8(3):479.

10. Naseem H, Wall AP, Sangster M, Paton RW. The presentation of rickets to orthopaedic clinics: return of the English disease. Acta Orthop Belg. 2011;77(2):239-45.

11. Kimlin M, Sun J, Sinclair C, Heward S, Hill J, Dunstone K, et al. Are the current Australian sun exposure guidelines effective in maintaining adequate levels of 25-hydroxyvitamin D? J Steroid Biochem Mol Biol. 2016;155(Pt B):264-70.

12. Kockott D, Herzog B, Reichrath J, Keane K, Holick MF. New approach to develop optimized sunscreens that enable cutaneous vitamin D formation with minimal erythema risk. PLoS ONE. 2016;11(1):e0145509.

13. Juzeniene A, Moan J. Beneficial effects of UV radiation other than via vitamin D production. Dermatoendocrinol. 2012;4(2):109-17.

14. Fell GL, Robinson KC, Mao J, Woolf CJ, Fisher DE. Skin beta-endorphin mediates addiction to UV light. Cell. 2014;157(7):1527-34

15. van der Rhee H, Coebergh JW, de Vries E. Is prevention of cancer by sun exposure more than just the effect of vitamin D? A systematic review of epidemiological studies. Eur J Cancer. 2013;49(6):1422-36.

16. Weller RB. Sunlight has cardiovascular benefits independently of vitamin D. Blood Purif. 2016;41(1-3):130-4.

17. Beveridge LA, Struthers AD, Khan F, Jorde R, Scragg R, Macdonald HM, et al. Effect of vitamin D supplementation on blood pressure: a systematic review and meta-analysis incorporating individual patient data. JAMA Intern Med. 2015;175(5):745-54.

18. Liu D, Fernandez BO, Hamilton A, Lang NN, Gallagher JMC, Newby DE, et al. UVA irradiation of human skin vasodilates arterial vasculature and lowers blood pressure independently of nitric oxide synthase. J Invest Dermatol. 2014;134(7):1839-46.

19. Oplander C, Volkmar CM, Paunel-Gorgulu A, van Faassen EE, Heiss C, Kelm M, et al. Whole body UVA irradiation lowers systemic blood pressure by release of nitric oxide from intracutaneous photolabile nitric oxide derivates. Circ Res. 2009;105(10):1031-40.

20. Feelisch M, Kolb-Bachofen V, Liu D, Lundberg JO, Revelo LP, Suschek CV, et al. Is sunlight good for our heart? Eur Heart J. 2010;31(9):1041-5.

21. Palmer RM, Ferrige AG, Moncada S. Nitric oxide release accounts for the biological activity of endothelium-derived relaxing factor. Nature. 1987;327(6122):524-6.

22. Cowburn AS, Takeda N, Boutin AT, Kim JW, Sterling JC, Nakasaki M, et al. HIF isoforms in the skin differentially regulate systemic arterial pressure. Proc Natl Acad Sci USA. 2013;110(43):17570-5.

23. Halliday GM, Byrne SN. An unexpected role: UVA-induced release of nitric oxide from skin may have unexpected health benefits. J Invest Dermatol. 2014;134(7):1791-4.
24. Murray CJ, Ezzati M, Flaxman AD, Lim S, Lozano R, Michaud C, et al. GBD 2010: design, definitions, and metrics. Lancet. 2012;380(9859):2063-6.

25. Johnson RS, Titze J, Weller R. Cutaneous control of blood pressure. Curr Opin Nephrol Hypertens. 2016;25(1):11-5.

26. Mahmoud BH, Ruvolo E, Hexsel CL, Liu Y, Owen MR, Kollias $\mathrm{N}$, et al. Impact of long-wavelength UVA and visible light on melanocompetent skin. J Invest Dermatol. 2010;130(8):2092-7.

27. Kohli I, Chaowattanapanit S, Mohammad TF, Nicholson CL, Fatima S, Jacobsen G, et al. Synergistic effects of long wavelength ultraviolet al and visible light on pigmentation and erythema. $\mathrm{Br}$ J Dermatol. 2018;178(5):1173-80.

28. Diffey B, Cadars B. An appraisal of the need for infrared radiation protection in sunscreens. Photochem Photobiol Sci. 2016;15(3):361-4.

29. Lohr NL, Keszler A, Pratt P, Bienengraber M, Warltier DC, Hogg $\mathrm{N}$. Enhancement of nitric oxide release from nitrosyl hemoglobin and nitrosyl myoglobin by red/near infrared radiation: potential role in cardioprotection. J Mol Cell Cardiol. 2009;47(2):256-63.

30. Piazena H, Kelleher DK. Effects of infrared-A irradiation on skin: discrepancies in published data highlight the need for an exact consideration of physical and photobiological laws and appropriate experimental settings. Photochem Photobiol. 2010;86(3):687-705.

31. Osterwalder U, Hareng L. Global UV filters: current technologies and future innovations. In: Wang S, Lim H, editors. Principles and practice of photoprotection. Cham: Adis; 2016.

32. Osterwalder U, Herzog B, Wang SQ. Advance in sunscreens to prevent skin cancer. Expert Rev Dermatol. 2011;6(5):479-91.

33. Brandt M, Rohr M, Schrader A. Influence of VIS/NIR radiation on the characteristics of sunscreen and human skin. IFSCC Magazine. 2001;4(1):15-9.

34. Ramos S, Homem V, Alves A, Santos L. A review of organic UVfilters in wastewater treatment plants. Environ Int. 2016;86:24-44.

35. Lawrence KP, Long PF, Young AR. Mycosporine-like amino acids for skin photoprotection. Curr Med Chem. Epub. 2017. https://doi. org/10.2174/0929867324666170529124237.

36. Shick JM, Dunlap WC. Mycosporine-like amino acids and related Gadusols: biosynthesis, acumulation, and UV-protective functions in aquatic organisms. Annu Rev Physiol. 2002;64:223-62.

37. Fajuyigbe D, Young AR. The impact of skin colour on human photobiological responses. Pigment Cell Melanoma Res. 2016;29(6):607-18.

38. Nasti TH, Timares L. MC1R, eumelanin and pheomelanin: their role in determining the susceptibility to skin cancer. Photochem Photobiol. 2015;91(1):188-200.

39. Cestari T, Buster K. Photoprotection in specific populations: children and people of color. J Am Acad Dermatol. 2017;76(3S1):S110-21.

40. Stengel FM, Fernandez JF. Education and behavioral change for sun protection. J Cosmet Dermatol. 2005;4(2):83-8.

41. Matsuoka LY, Ide L, Wortsman J, MacLaughlin JA, Holick MF. Sunscreens suppress cutaneous vitamin D3 synthesis. J Clin Endocrinol Metab. 1987;64(6):1165-8.

42. Parrish JA, Jaenicke KF, Anderson RR. Erythema and melanogenesis action spectra of normal human skin. Photochem Photobiol. 1982;36(2):187-91.

43. de Gruijl FR. Skin cancer and solar UV radiation. Eur J Cancer. 1999;35(14):2003-9. 